\title{
CEREBRAL DYSFUNCTION AFTER CORONARY ARTERY BYPASS GRAFTING DONE WITH MILD OR MODERATE HYPOTHERMIA
}

Eric J. Heyer, MD, $\mathrm{PhD}^{\mathrm{a}, \mathrm{b}}$

David C. Adams, MD ${ }^{a}$

Ellise Delphin, $\mathrm{MD}^{\mathrm{a}}$

Donald J. McMahon, $\mathrm{MS}^{\mathrm{d}}$

Susan D. Steneck, PhD ${ }^{\mathrm{a}}$

Mehmet C. Oz, $\mathrm{MD}^{\mathrm{c}}$

Robert E. Michler, MD ${ }^{c}$

Eric A. Rose, $\mathrm{MD}^{\mathrm{c}}$

\begin{abstract}
Objective: Ninety-nine patients undergoing elective coronary artery bypass grafting were enrolled in a prospective, randomized study to evaluate the incidence of cerebral dysfunction after "mild" or "moderate" hypothermia during cardiopulmonary bypass. Methods: Patients were evaluated before and after operation before hospital discharge and in some cases at follow-up at least 6 weeks later with a complete neurologic examination (85 patients) and a battery of standard neuropsychometric tests (86 patients). Results: Postoperative changes detected by neurologic examination consisted of the appearance of new primitive reflexes in both groups. No statistically significant differences in incidence were found. The neuropsychometric performances of the two groups were statistically similar by either event-rate or group-rate analysis. Conclusions: There is no detectable difference in postoperative cerebral dysfunction in patients undergoing coronary artery bypass grafting who are supported by cardiopulmonary bypass with either mild or moderate hypothermia. (J Thorac Cardiovasc Surg 1997;114:270-7)
\end{abstract}

$\mathrm{N}$ eurologic injury develops in a significant percentage of patients who undergo a cardiac operation with the use of cardiopulmonary bypass (CPB). ${ }^{1,2}$ In early reports, the manifestation of this injury was seen as stroke ${ }^{3}$ or postcardiotomy delirium, ${ }^{4}$ but now more subtle injuries occur, which require a battery of neuropsychometric tests to recognize. ${ }^{1}$ Although the cause of neurologic injury has not been definitively established, emboli probably play a significant role in its production. In this

From the Departments of Anesthesiology, ${ }^{\mathrm{a}}$ Neurology, ${ }^{\mathrm{b}}$ and Surgery (Cardiothoracic Division) ${ }^{c}$ and The Irving Center for Clinical Research, ${ }^{\mathrm{d}}$ Columbia University, New York, N.Y.

Supported in part by a grant-in-aid award to Dr. Heyer from the American Heart Association, New York City Affiliate; by a grant to Dr. Adams from the CPMC Office of Clinical Trials, New York, N.Y.; and by grant 5 MO1 RR00645 to Dr. McMahon from the National Institutes of Health, Division of Research Resources, General Clinical Research Centers Program. Dr. Heyer is a Herbert Irving Assistant Professor of Anesthesiology. Dr. Oz is a Herbert Irving Assistant Professor of Surgery.

Received for publication May 23, 1996; revisions requested Dec. 26, 1996; revisions received Jan. 20, 1997; accepted for publication Feb. 21, 1997.

Address for reprints: Eric J. Heyer, MD, PhD, Department of Anesthesiology, Columbia University, PH 5-535, 630 West 168th St., New York, NY 10032-3784.

Copyright $(1) 1997$ by Mosby-Year Book, Inc.

$0022-5223 / 97 \$ 5.00+0 \quad \mathbf{1 2 / 1 / 8 1 3 9 3}$ regard, improvements in CPB techniques have decreased the load of particulate material generated and thereby the more devastating manifestations of this injury. ${ }^{5}$ Hypothermia has been the cerebral protective therapy most commonly used. Until relatively recently, hypothermia was maintained at "moderate" temperatures $\left(28^{\circ} \mathrm{C}\right)$. However, many cardiothoracic surgeons are now inclined to perform cardiac operations with "mild" hypothermia $\left(34^{\circ} \mathrm{C}\right)$. Although one large study demonstrated an increase in stroke rate when CPB was maintained at "normothermia," there is some evidence that patients operated on with CPB maintained at mild hypothermia have no greater incidence of cerebral injury than those in which CPB was done at colder temperatures. $^{7}$

Because hypothermia is one of the most effective measures to protect the brain, it is important to demonstrate that there is no increase in cerebral dysfunction under mild hypothermic conditions. The one study in which the investigators looked at the effect of mild versus moderate hypothermia during CPB primarily evaluated groups of patients by group-rate analysis and did not specifically substratify patients as a function of age to be certain that equal percentages of elderly patients were in each group. ${ }^{7}$ In the current investigation we compared the incidence of cerebral dysfunction in patients stratified by age into two groups, young and 
elderly, and maintained with moderate $\left(28^{\circ} \mathrm{C}\right.$; group A) or mild $\left(34^{\circ} \mathrm{C}\right.$; group $\left.\mathrm{B}\right)$ hypothermia during CPB. The results are analyzed both by eventrate analysis, in which each patient's postoperative performance is compared with his or her own preoperative performance for the individual tests as a whole, and by group-rate analysis, in which group means and variances for each test are compared before and after the operation.

\section{Methods}

Ninety-nine consecutive patients undergoing elective coronary artery bypass grafting $(\mathrm{CABG})$ were recruited to participate in this study approved by the institutional review board. All patients with evidence of preexisting neurologic or psychiatric illness were excluded. After informed written consent was obtained, patients were assessed before operation with the use of both neurologic and neuropsychometric tests. All patients were allocated into group $\mathrm{A}\left(28^{\circ} \mathrm{C}\right)$ or group $\mathrm{B}\left(34^{\circ} \mathrm{C}\right)$ by randomization within two strata of patient age: young $(<65$ years) and elderly ( $\geq 65$ years). The treatment allocation assigned by randomization was revealed to the surgical staff after the induction of anesthesia and before the start of the operation. Neurologic and neuropsychometric tests were repeated about 6 days after the operation (early tests). When patients returned for a follow-up visit with the cardiothoracic surgeon 6 to 9 weeks after hospital discharge, the neuropsychometric test battery was repeated (late tests). All examinations were performed 3 or more hours after any analgesic or sedative medication was administered.

Anesthesia. All patients were premedicated with oral diazepam ( 0.1 to $0.15 \mathrm{mg} / \mathrm{kg}$ ), intramuscular morphine $(0.1 \mathrm{mg} / \mathrm{kg})$, and intramuscular scopolamine $(0.3 \mathrm{mg})$. General anesthesia was induced with fentanyl, midazolam, and vecuronium and maintained with fentanyl and midazolam (average total doses [standard deviation] 63.8 [18.7] $\mu \mathrm{g} / \mathrm{kg}$ and 0.19 [0.09] mg/kg, respectively) and isoflurane ( 0 to 0.5 exp) as tolerated. All hemodynamic data plus temperature were monitored continuously and recorded every minute by a PC-based data acquisition system (either Lifelog from $\mathrm{MI}^{2}$, Rosemont, Pa., or LabView from National Instruments, Austin, Tex. ${ }^{8}$ ). Temperature was recorded from the axilla, blood, and nasopharynx in all patients. The target temperature during $\mathrm{CPB}$ was defined as the nasopharyngeal temperature.

Operations and CPB. All operations were performed by one of three surgeons. The operation consisted of CABG procedures only with no patients having reoperation. Exposure was by a median sternotomy. Anticoagulation was achieved with heparin (300 units $/ \mathrm{kg}$ ) and supplemented with additional doses to maintain an activated clotting time more than 400 seconds (Hemochron 8000, International Technidyne Co., Edison, N.J.). The CPB system consisted of a centrifugal arterial pump (Medtronic Bio-Medicus, Eden Prairie, Minn.), a hollowfiber membrane oxygenator (Baxter Univox, Irvine, Calif.), a Sarns TCM (temperature control mechanism) heater-cooler, and a $40 \mu \mathrm{m}$ arterial line filter (Pall Bio- medical Products, Glen Cove, N.Y.). No active methods of temperature control were used before $\mathrm{CPB}$, although many patients spontaneously cooled to close to $34^{\circ} \mathrm{C}$. Specifically, ice packs to the head were not used. During $\mathrm{CPB}$, nonpulsatile flow rates of $2.4 \mathrm{~L} / \mathrm{min}$ per square meter and alpha-stat management of $\mathrm{pH}$ were used. In some cases, vasoactive medications such as phenylephrine or sodium nitroprusside were administered during CPB to maintain the mean arterial pressure between 55 and 70 $\mathrm{mm} \mathrm{Hg}$. The coronary arteries were perfused with anterograde and retrograde cold blood cardioplegic solution constituted with a blood-to-crystalloid ratio of 4:1. All operations were done with a single crossclamp technique to avoid additional trauma to the ascending aorta caused by use of a partial occluding clamp. The crossclamp was applied before the target temperature was attained and rewarming began 10 minutes before its removal. The heart was evacuated of air by a variety of mechanical techniques, the most common being ascending aortic venting; however, carbon dioxide was not used to flood the operative field.

Neurologic and neuropsychometric evaluation for cerebral dysfunction. The neurologic examination was a structured evaluation that consisted of a quantitative mini-mental status component, an evaluation of cranial nerves and motor, sensory and cerebellar systems in addition to gait, station, deep tendon and primitive reflexes (snout, grasp, palmomental, and glabellar). ${ }^{9}$ The postoperative neurologic examination was scored as either changed or unchanged as compared with results of the preoperative examination.

Nine scores were generated from the quantitative minimental status test and a battery of four neuropsychometric tests, each of which was chosen to evaluate a different cognitive domain ${ }^{10,11}$ : Halstead-Reitan Trails Test Parts $\mathrm{A}$ and $\mathrm{B},{ }^{10}$ right and left index finger tapping test,${ }^{10}$ grooved pegboard test ${ }^{10}$ with dominant and nondominant hands, and long-term retrieval and consistency of longterm retrieval on the Buschke Selective Reminding Test. ${ }^{12}$ Except for our substitution of the Buschke Selective Reminding Test for an equivalent test, the Rey Auditory Verbal Learning Test, all of our neuropsychometric tests were part of a core neuropsychologic battery recommended by a consensus group. ${ }^{13}$

Any new neurologic finding was considered of significance. The incidence of new neurologic findings was compared between groups with the $\chi^{2}$ test. With eventrate comparisons, each patient's overall neuropsychometric performance was assessed by comparing preoperative and postoperative scores for each test. For an individual test result to be considered abnormal there had to be at least a $25 \%$ decrease in postoperative performance compared with preoperative results.

Statistical measures. Comparability of groups on baseline continuous measures was analyzed by a two-tailed Student's $t$ test and baseline categorical variables by $\chi^{2}$ analysis. The difference in the proportion of patients with new neurologic findings in each group was compared by a $\chi^{2}$ test. The group difference in the number of new postoperative neuropsychometric test abnormalities in each patient was compared by a Mann-Whitney rank sum 
Table I. Preoperative, intraoperative, and postoperative profile

\begin{tabular}{lcc}
\hline & $\begin{array}{c}\text { Group A } \\
\left(28^{\circ} \mathrm{C}\right)\end{array}$ & $\begin{array}{c}\text { Group B } \\
\left(34^{\circ} \mathrm{C}\right)\end{array}$ \\
\hline Age (yr) & $64.4(11.9)$ & $63.5(10.4)$ \\
Young (yr) & $54.5(6.7)$ & $53.7(6.7)$ \\
Elderly (yr) & $74.2(6.4)$ & $71.0(4.9)^{*}$ \\
Gender (male:female) & $35: 11$ & $46: 7$ \\
Height (cm) & $162.1(36.9)$ & $162.0(42.2)$ \\
Weight (kg) & $81.3(16.6)$ & $84.6(13.6)$ \\
Education (yr) & $14.3(3.1)$ & $15.3(7.3)$ \\
Duration of operation (min) & $297.2(72.8)$ & $267.2(52.5)^{*}$ \\
Time to extubation (hr) & $17.5(7.7)$ & $16.5(5.9)$ \\
Bypass time (min) & $112.8(29.5)$ & $105.7(24.1)$ \\
Crossclamp time (min) & $73.0(27.6)$ & $70.4(21.5)$ \\
Lowest MAP & $53.8(7.6)$ & $52.3(7.9)$ \\
\hline
\end{tabular}

Values given as mean with standard deviation in parentheses. $M A P$, Mean arterial pressure.

${ }^{*} p<0.05$ compared with group A elderly.

test on zero, only one, only two, only three, or four or more abnormal test results. This categorization of deficit was used because more than four abnormal test results is generally considered indicative of significantly impaired neuropsychometric performance. ${ }^{1}$ Multivariate analysis of variance (MANOVA) of the difference scores on the nine neuropsychometric tests (preoperative minus early test and preoperative minus late test) evaluated the effects of $\mathrm{CPB}$ temperature $\left(28^{\circ} \mathrm{C}\right.$ vs $\left.34^{\circ} \mathrm{C}\right)$ and subject age $(<65$ years vs $\geq 65$ years old) and the interaction of $C P B$ temperature and subject age. The effect of adding internal thoracic artery grafts to the surgical procedure was evaluated by MANOVA. Multivariate analyses were done with the SAS Proc GLM program (SAS Institute, Cary, N.C.). All statistical tests were evaluated with a two-tailed type 1 error rate of $5 \%$.

Before initiation of this study, a sample size of 50 subjects in each CPB temperature group was calculated as required to provide $80 \%$ power to detect a $25 \%$ difference in postoperative individual neuropsychometric performance caused by CPB temperature by an analysis of variance with a $5 \%$ rejection criterion.

\section{Results}

The two groups, $\mathrm{A}\left(28^{\circ} \mathrm{C}\right)$ and $\mathrm{B}\left(34^{\circ} \mathrm{C}\right)$, consisted of 46 and 53 patients, respectively. The groups were statistically comparable for demographic and anesthetic variables (Table I). Group B had a statistically shorter duration of operation (Table I). Each age subgroup was statistically comparable between groups $(64.4 \pm 11.9$ and $63.5 \pm 10.4$ years $)$, except that the elderly were younger in group $\mathrm{B}$ $(74.2 \pm 6.4$ years in group $A$ vs $71.0 \pm 4.9$ years in group B) (Table I).

Patients were evaluated before and after operation before hospital discharge (early test) with use of a complete neurologic examination (85 patients)
Table II. Changes in neurologic examination

Group A $(14 / 40$ patients $=35.0 \%)$
Palmomental reflexes: unilateral, bilateral
Snout
Grasp
Hoffman
Jaw jerk
Decreased left arm strength
Group B $(12 / 45$ patients $=26.7 \%)$
Palmomental reflexes: unilateral, bilateral
Snout
Grasp
Hoffman
Jaw jerk
Decreased stereognosis and graphesthesia
Left hand weakness
Right inferotemporal visual field hemianopia

and a battery of standard neuropsychometric tests (86 patients) and at surgical follow-up (late test) with neuropsychometric tests (26 patients). Approximately one third of the patients were unavailable for late examination because they did not return to the surgeon for follow-up inasmuch as they lived more than 50 miles from the hospital and therefore were seen by their local cardiologists. The total number of patients is greater than the number of patients having neurologic and neuropsychometric evaluations because some patients missed one evaluation but not the other. The early and late follow-up examinations were performed at statistically comparable postoperative days for groups $\mathrm{A}$ and $\mathrm{B}$ (6.7 vs 5.7 days, $p=0.06 ; 44.7$ vs 42.9 days, $p=0.50$, respectively).

Eighty-eight percent of the patients had neurologic examinations both before the operation and in the early follow-up period (Table II). Subtle deficits were detected by neurologic examination in $35.0 \%$ $(14 / 40)$ of group A patients and in $26.7 \%(12 / 45)$ of group B patients in this period $(p=0.41)$. However, there were no significant differences in postoperative neurologic performances between pooled results for groups A or B ( $p=0.55, \chi^{2}$ test) or for the groups substratified by age (young, $p=0.75$; elderly, $p=0.33$ ). The neurologic findings consisted of the presence of palmomental, grasp, snout, and Hoffman reflexes that had not existed before operation. In addition, one patient in group A had arm weakness that developed after the operation, one patient in group B had hand weakness, two patients had problems with graphesthesia and stereognosis, and one patient developed a visual field hemianopsia. The number of patients with new neurologic find- 
Table III. Abnormal neuropsychometric test results

\begin{tabular}{lcc}
\hline \multirow{2}{*}{$\begin{array}{c}\text { No. of abnormal } \\
\text { test results }\end{array}$} & \multicolumn{2}{c}{ Percent with abnormal results } \\
\cline { 2 - 3 } & Group $A$ & Group $B$ \\
\hline Early follow-up* & $n=46$ & $n=53$ \\
Zero & 19.57 & 28.30 \\
Only one & 19.57 & 24.53 \\
Only two & 32.62 & 28.30 \\
Only three & 17.39 & 7.55 \\
Four or more & 10.87 & 11.32 \\
& & \\
Late follow-up $\dagger$ & $n=13$ & $n=13$ \\
Zero & 38.46 & 30.77 \\
Only one & 46.15 & 30.77 \\
Only two & 15.38 & 30.77 \\
Only three & 0.00 & 0.00 \\
Four or more & 0.00 & 7.69 \\
\hline
\end{tabular}

${ }^{*} p=0.297$ by Mann-Whitney rank sum test. $\dagger p=0.330$ by Mann-Whitney rank sum test.

ings was equally distributed between the two age groups.

There was no statistically significant decline in the number of abnormal neuropsychometric test results in comparing groups $\mathrm{A}$ and $\mathrm{B}$ in the early or late follow-up periods (Mann-Whitney rank sum test, $p=0.30$ for early and $p=0.33$ for late follow-up) (Tables III and IV, Fig. 1). Likewise, there were no significant differences in postoperative neuropsychometric performance for the groups substratified by age in the early follow-up period (Mann-Whitney rank sum test: young, $p=0.22$; elderly, $p=0.56$ ). Test results improved significantly between early and late follow-up examinations (Table III, Fig. 1). No comparisons of preoperative to early or late neuropsychometric test score means attained statistical significance by temperature, age, or temperature-age interactions (Table IV, Fig. 2).

The consistency of the neuropsychometric tests was as follows. No patient with three or more abnormal test results at early follow-up had any abnormal test results in new cognitive domains at late follow-up. However, 2 of 10 patients with one or two abnormal test results and 7 of 14 patients with no abnormal test results at early follow-up had abnormal test results in one new cognitive domain at late follow-up.

\section{Discussion}

Mild and moderate cerebral hypothermia have been demonstrated to provide cerebral protection when evaluated by group-rate analysis. ${ }^{7}$ However, comparing patients by group-rate analysis may fail
Table IV. Neuropsychologic test scores

\begin{tabular}{lcc}
\hline & Group A & Group B \\
\hline Preoperative & & \\
Mini-mental status & $52.6(3.7)$ & $52.9(2.9)$ \\
Trails A & $42.8(17.7)$ & $39.2(14.6)$ \\
Trails B & $101.9(55.3)$ & $92.8(54.4)$ \\
Repetitive tapping: dom. & $50.3(11.2)$ & $51.4(9.4)$ \\
Repetitive tapping: nondom. & $46.9(8.5)$ & $46.0(10.0)$ \\
Buschke: LTR & $91.9(24.6)$ & $96.0(31.2)$ \\
Buschke: CLTR & $52.8(26.9)$ & $57.0(29.9)$ \\
Grooved pegboard: dom. & $120.8(35.3)$ & $122.4(26.7)$ \\
Grooved pegboard: nondom. & $141.8(47.7)$ & $130.1(24.4)$ \\
& & \\
Early follow-up & & \\
Mini-mental status & $52.2(4.2)$ & $53.2(2.7)$ \\
Trails A & $42.8(19.9)$ & $37.9(14.6)$ \\
Trails B & $111.7(66.4)$ & $110.5(69.7)$ \\
Repetitive tapping: dom. & $49.1(7.8)$ & $48.5(11.1)$ \\
Repetitive tapping: nondom. & $44.7(6.8)$ & $45.1(9.9)$ \\
Buschke: LTR & $70.6(23.5)$ & $74.5(25.5)$ \\
Buschke: CLTR & $38.9(20.5)$ & $42.8(23.8)$ \\
Grooved pegboard: dom. & $130.8(43.3)$ & $127.1(31.5)$ \\
Grooved pegboard: nondom. & $158.9(74.9)$ & $140.2(40.2)$ \\
& & \\
Late follow-up & & \\
Mini-mental status & $54.3(3.0)$ & $52.7(4.0)$ \\
Trails A & $33.5(10.6)$ & $36.6(14.6)$ \\
Trails B & $90.1(55.7)$ & $74.6(52.2)$ \\
Repetitive tapping: dom. & $56.4(5.7)$ & $54.5(10.0)$ \\
Repetitive tapping: nondom. & $48.6(6.1)$ & $46.4(8.4)$ \\
Buschke: LTR & $79.8(30.5)$ & $76.7(35.3)$ \\
Buschke: CLTR & $53.5(28.1)$ & $46.4(32.1)$ \\
Grooved pegboard: dom. & $110.3(24.6)$ & $104.4(16.7)$ \\
Grooved pegboard: nondom. & $117.2(28.3)$ & $109.6(14.7)$ \\
\hline & & \\
Gas & & \\
& & \\
& & \\
& &
\end{tabular}

Values given as mean with standard deviation in parentheses. dom., Dominant hand; nondom., nondominant had; LTR, long-term retrieval; $C L T R$, consistency of long-term retrieval.

to demonstrate that some patients have a decrease in performance whereas others improve. For this reason, we evaluated patient performance by both group-rate and event-rate analysis. In addition, we subdivided the patients into two age groups, because age is an important confounding variable. ${ }^{14-16} \mathrm{El}-$ derly patients have been shown to demonstrate more changes on neuropsychometric tests after cardiac operations. ${ }^{14,15}$ Our groups had equal numbers of patients younger than age 65 years and age 65 or older.

The criteria chosen to define abnormality can affect the reported incidence of cerebral dysfunction. ${ }^{17}$ The neurologic examination result was defined as abnormal if there were any new findings on follow-up examination. This definition was chosen instead of a scored evaluation, because scored examinations do not include evaluations of the type of 


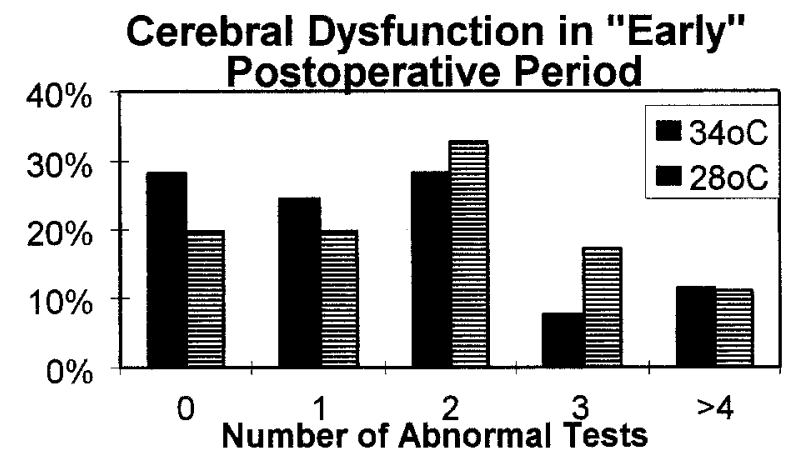

\section{Cerebral Dysfunction in "Late" Postoperative Period}

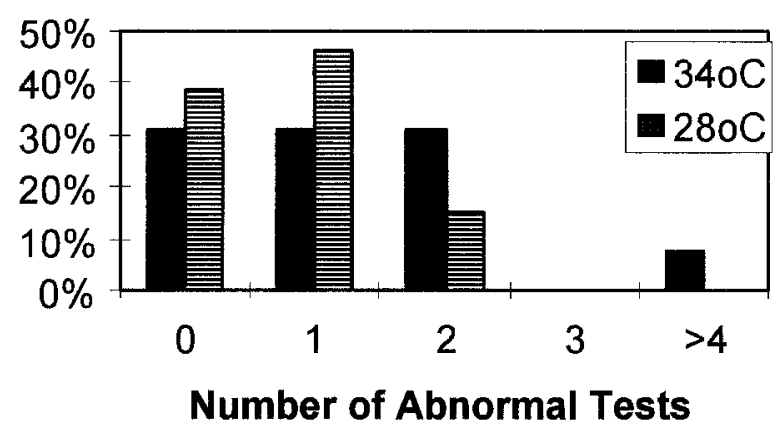

Fig. 1. Histograms of cerebral dysfunction in the early and late postoperative periods for group $\mathrm{A}\left(28^{\circ} \mathrm{C}\right)$ and group $\mathrm{B}\left(34^{\circ} \mathrm{C}\right)$ comparing the percentages of patients with only one, only two, only three, or four or more abnormal neuropsychometric test results. Results of examinations done in the early period are given at the top and results from the late period are at the bottom.

subtle changes seen after cardiac operations. Furthermore, the significance of a change in score does not correlate with either the area of cerebral tissue damaged or the number of lesions. ${ }^{9}$ There is considerable literature regarding the criteria used to score neuropsychometric tests. ${ }^{17}$ Our criteria for change tended to underestimate the number of patients with abnormal findings because by defining abnormality as a decrease of $25 \%$ or more, the mean change was between one and two standard deviations on most tests that were highly age dependent, such as the Reitan Trails Test Parts A and B and the Buschke Selective Reminding Test. In addition, a percentage change minimizes the problem posed by patients who score significantly below the mean on the baseline examination and therefore cannot show abnormal results on follow-up examinations, if a decrease by one standard deviation or more is used as a criterion. In fact, Mahanna and associates ${ }^{17}$ found this to be a problem in more than a third of their cases.

Many investigators in this area use the number of abnormal individual test scores as a measure of severity of cerebral dysfunction. Because this measure is somewhat arbitrary, we compared our groups by the distribution of abnormal test scores. A nonparametric measure of differences, such as the Mann-Whitney rank sum test, is then used to test these distributions. Despite these concerns, our results are not significantly different from those of others. $^{1,18-20}$ Because our goal was to compare findings in patients undergoing CPB done with either mild or moderate hypothermia, and changes were most pronounced for the early follow-up period, evaluations for this period were considered more important. Therefore all statistical comparisons with the greatest power were performed on the basis of this period.

Generally the performance of patients with one or more abnormal neuropsychometric test results at early follow-up improved by late follow-up. However, 2 of 16 patients had an abnormality develop in a new cognitive area, and about half of the patients with no abnormal test results at early follow-up had an abnormal test result at late follow-up. We cannot be certain whether these new abnormal test results in different cognitive domains denoted new cerebral injury or test result fluctuation by chance. Although we were disappointed that we could not include more patients for evaluation at late follow-up, no studies have shown that significantly more patients have abnormalities that develop at these later times. ${ }^{1,2,18}$ Therefore we are confident that important conclusions can be derived from the early follow-up period.

Cerebral injury arises from insufficient global or focal cerebral blood flow. Under most circumstances, global cerebral blood flow is adequate to meet cerebral metabolic demands with alpha-stat blood gas management and is probably in excess of these demands with $\mathrm{pH}$-stat blood gas management. ${ }^{21}$ On the other hand, there are potentially many sources of emboli that can produce focal cerebral blood flow insufficiency. There is now evidence that the number of emboli correlates with the frequency of finding cerebral dysfunction. ${ }^{19}$ Emboli are found to arise at multiple times during cardiac operations. ${ }^{19,22,23}$ One common time is at the initiation and termination of CPB. ${ }^{19,22}$ At these times, 


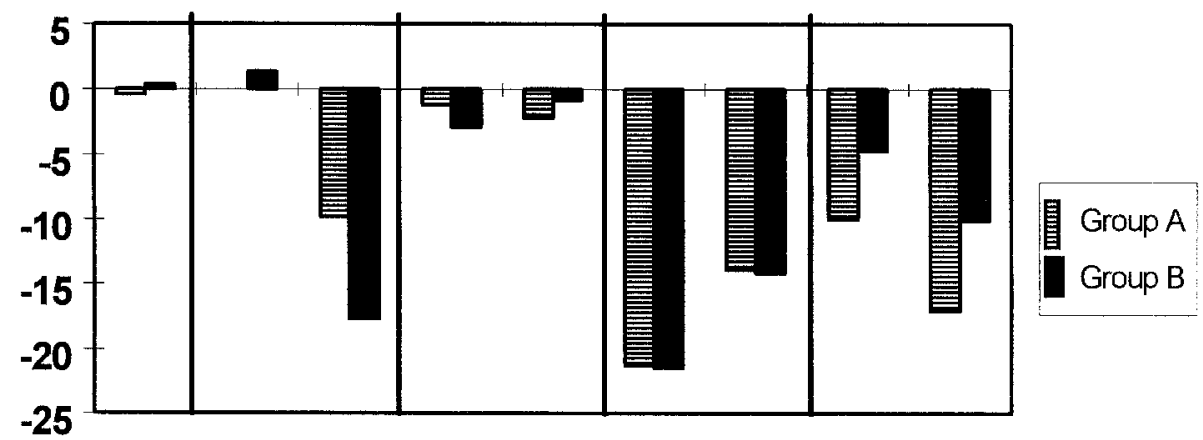

Late Follow-Up

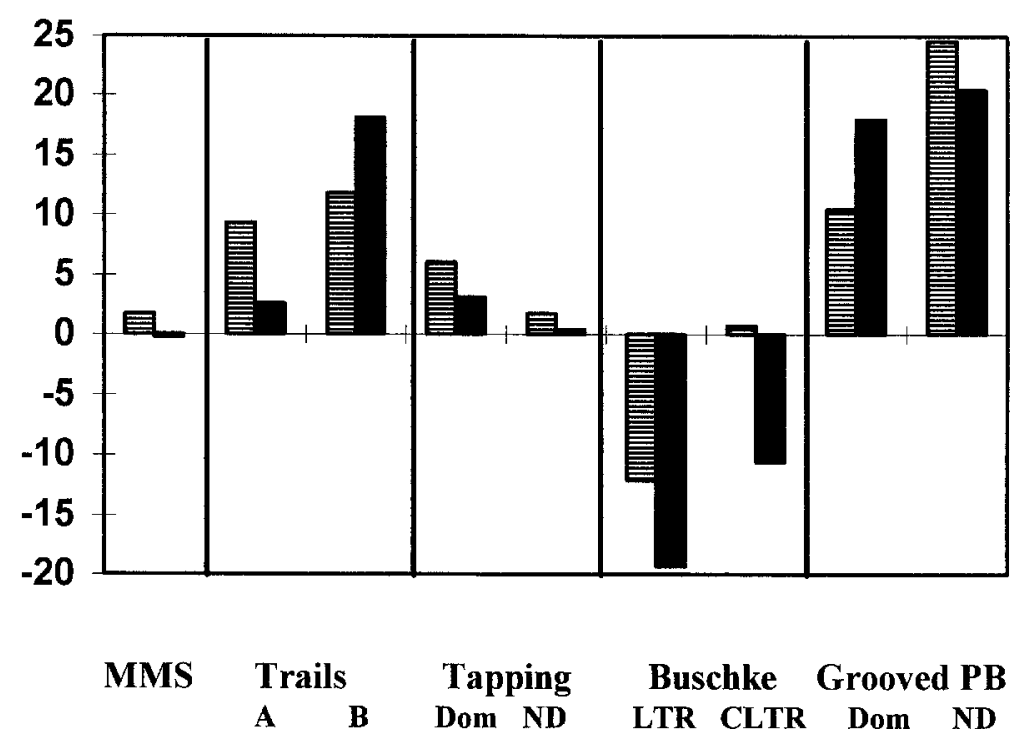

Fig. 2. Histograms for group A $\left(28^{\circ} \mathrm{C}\right)$ and group B $\left(34^{\circ} \mathrm{C}\right)$ comparing neuropsychologic test score differences between early and late postoperative periods with the preoperative assessment for each neuropsychometric test. Positive numbers reflect improved performance and negative numbers deterioration in performance. The nine tests are denoted at the bottom for both graphs. There were no significant differences between the two groups. $M M S$, Quantitative mini-mental status component; Trails $A$ and $B$, Halstead-Reitan Trails Test Parts A and B; Tapping, right and left index finger tapping test; Dom, dominant hand; ND, nondominant hand; Buschke, Buschke Selective Reminding Test; LTR, long-term retrieval; $C L T R$, consistency of long-term retrieval; Grooved $P B$, grooved pegboard test.

patients are at relatively warm temperatures compared with the hypothermic temperatures that can be and frequently are used during CPB. Therefore with newer $\mathrm{CPB}$ techniques the importance of hypothermia during CPB may be less significant than the temperature at initiation and termination of CPB.
Whereas cerebral protection from hypothermia was thought to result from reduction in the cerebral metabolic rate, it is now thought that reduction of excitatory neurotransmitter release from glutaminergic terminals might play a more significant role. $^{24,25}$ In fact, even though cerebral metabolism is reduced by only a small amount when the brain 
temperature is reduced by a few degrees (about $3^{\circ} \mathrm{C}$ ), both excitatory neurotransmitter release and cerebral injury are attenuated dramatically. ${ }^{25}$ This small decrement of temperature should not be confused with "normothermia." A large study with patients maintained at either normothermia $\left(\geq 35^{\circ} \mathrm{C}\right)$ or moderate hypothermia $\left(\leq 28^{\circ} \mathrm{C}\right)$ showed a significantly higher rate of stroke $(3.1 \%$ vs $1.0 \% ; p \leq 0.02)$ and total neurologic events $(4.5 \%$ vs $1.4 \% ; p<0.005)$ in the warmer group. ${ }^{6}$ These results have been confirmed recently by two other groups. $^{26,27}$

Our groups were established by randomizing patients as to temperature and age. Because the main question that we investigated was the effect of temperature during $\mathrm{CPB}$, we did not want one of the main confounding variables, age, to bias one group disproportionately. Indeed, the groups were comparable except for the shorter duration of operation and slightly younger age of the elderly patients in group B (mild hypothermia). Although we do not have evidence that this small difference in age in the subgroup of patients 65 years old or older ( 3.2 years, Table I) is insignificant in terms of neuropsychometric performance, it seems unlikely that it would significantly affect performance on these tests. The shorter duration of CPB in group B was likely because these patients did not require as much rewarming intraoperatively (Table I).

We thank Dr. Alvin Wald for reviewing the manuscript.

\section{REFERENCES}

1. Shaw PJ, Bates D, Cartlidge NEF, et al. Neurologic and neuropsychological morbidity following major surgery: comparison of coronary artery bypass and peripheral vascular surgery. Stroke 1987;18:700-7.

2. Furlan AJ, Sila CA, Chimowitz MI, Jones SC. Neurologic complications related to cardiac surgery [Review]. Neurol Clin 1992;10:145-66.

3. Gilman S. Cerebral disorders after open-heart operations. N Engl J Med 1965;272:489-98.

4. Kornfeld DS, Heller SS, Frank KA, Edie RN, Barsa J. Delirium after coronary artery bypass surgery. J Thorac Cardiovasc Surg 1978;76:93-6.

5. Padayachee TS, Parsons S, Theobold R, Gosling RG, Deverall PB. The effect of arterial filtration on reduction of gaseous microemboli in the middle cerebral artery during cardiopulmonary bypass. Ann Thorac Surg 1988;45: $647-9$.

6. Martin TD, Craver JM, Gott JP, et al. Prospective, randomized trial of retrograde warm blood cardioplegia: myocardial benefit and neurologic threat. Ann Thorac Surg 1994;57:298304.
7. McLean RF, Wong BI, Naylor CD, et al. Cardiopulmonary bypass, temperature, and central nervous system dysfunction. Circulation 1994;90(5 pt 2):II250-5.

8. Heyer EJ, Wald A, Mencke A. Intraoperative data acquisition for the study of cerebral dysfunction following cardiopulmonary bypass. J Clin Monit 1995;11:305-10.

9. Heyer EJ, Adams DC. Neurological assessment and cardiac surgery. J Cardiothorac Vasc Anesth 1996;10:99-104.

10. Lezak MD. Neuropsychological assessment. 2nd ed. Oxford, New York: Oxford University Press, 1983.

11. Adams RD, Victor M. Principles of neurology. 3rd ed. New York: McGraw-Hill, 1985.

12. Buschke H, Fuld PA. Evaluating storage, retention, and retrieval in disordered memory and learning. Neurology 1974;24:1019-25.

13. Murkin JM, Newman SP, Stump DA, Blumenthal JA. Statement of consensus on assessment of neurobehavioral outcomes after cardiac surgery. Ann Thorac Surg 1995;59:128995.

14. Heyer EJ, Delphin E, Adams DC, et al. Cerebral dysfunction after cardiac operation in elderly patients. Ann Thorac Surg 1995;60:1716-22.

15. Slogoff S, Girgis KZ, Keats AS. Etiologic factors in neuropsychiatric complications associated with cardiopulmonary bypass. Anesth Analg 1982;61:903-11.

16. Tuman KJ, McCrthy RJ, Najafi H, Ivankovich AD. Differential effects of advanced age on neurologic and cardiac risks of coronary artery operations. J Thorac Cardiovasc Surg 1992;104:1510-7.

17. Mahanna EP, Blumenthal JA, White WD, et al. Defining neuropsychological dysfunction after coronary artery bypass grafting. Ann Thorac Surg 1996;61:1342-7.

18. Murkin JM, Martzke JS, Buchan AM, Bentley C, Wong CJ. A randomized study of the influence of perfusion technique and $\mathrm{pH}$ management strategy in 316 patients undergoing coronary artery bypass surgery. II. Neurologic and cognitive outcomes. J Thorac Cardiovasc Surg 1995; 110:349-62.

19. Stump DA, Rogers AT, Hammon JW, Newman SP. Cerebral emboli and cognitive outcome after cardiac surgery. J Cardiothorac Vasc Anesth 1996;10:113-9.

20. Venn GE, Patel RL, Chambers DJ. Cardiopulmonary bypass: perioperative cerebral blood flow and postoperative cognitive deficit. Ann Thorac Surg 1995;59:1331-5.

21. Murkin JM, Farrar JK, Tweed A, McKenzie FN, Guiraudon G. Cerebral autoregulation and flow/metabolism coupling during cardiopulmonary bypass: the influence of $\mathrm{PaCO}_{2}$. Anesth Analg 1987;66:825-32.

22. Barbut D, Hinton RB, Szatrowski TP, et al. Cerebral emboli detected during bypass surgery are associated with clamp removal. Stroke 1994;25:2398-402.

23. Barbut D, Yao FS, Hager DN, Kavanaugh P, Trifiletti RR, Gold JP. Comparison of transcranial Doppler ultrasonography and transesophageal echocardiography to monitor emboli during coronary artery bypass surgery. Stroke 1996;27: $87-90$.

24. Busto R, Dietrich WD, Globus MY-T, Valdes I, Scheinberg $\mathrm{P}$, Ginsberg MD. Small differences in intraischemic brain temperature critically determine the extent of ischemic neuronal injury. J Cereb Blood Flow Metab 1987;7: 729-38.

25. Busto R, Globus M-T, Dietrich W, Martinez E, Valders I, 
Ginsberg M. Effect of mild hypothermia on ischemia-induced release of neurotransmitters and free fatty acids in rat brain. Stroke 1989;20:904-10.

26. Mora CT, Henson MB, Weintraub WS, et al. The effects of temperature management during cardiopulmonary bypass on neurologic and neuropsychologic outcomes in patients un- dergoing coronary artery revascularization. J Thorac Cardiovasc Surg 1996;112:514-22.

27. Regragui I, Birdi I, Izzat MB, et al. The effects of cardiopulmonary bypass temperature on neuropsychologic outcome after coronary artery operations: a prospective randomized trial. J Thorac Cardiovasc Surg 1996;112:1036-45.

Don't miss a single issue of the journal! To ensure prompt service when you change your address, please photocopy and complete the form below.

Please send your change of address notification at least six weeks before your move to ensure continued service. We regret we cannot guarantee replacement of issues missed due to late notification.

\section{JOURNAL TITLE:}

Fill in the title of the journal here.

OLD ADDRESS:

Affix the address label from a recent issue of the journal here.

\section{NEW ADDRESS:}

Clearly print your new address here.

Name

Address

City/State/ZIP
COPY AND MAIL THIS FORM TO:

Journal Subscription Services Mosby-Year Book, Inc. 11830 Westline Industrial Dr. St. Louis, MO 63146-3318
OR FAX TO:

314-432-1158

N/ Mosby
OR PHONE:

1-800-453-4351

Outside the U.S., call

314-453-4351 